\title{
Estimating and tracking the remaining carbon budget for stringent climate targets
}

Joeri Rogelj $1,2,3 *$, Piers M. Forster ${ }^{4}$, Elmar Kriegler ${ }^{5}$, Christopher J. Smith Sl $^{4}$ Roland Séférian $^{6}$

\begin{abstract}
Research reported during the past decade has shown that global warming is roughly proportional to the total amount of carbon dioxide released into the atmosphere. This makes it possible to estimate the remaining carbon budget: the total amount of anthropogenic carbon dioxide that can still be emitted into the atmosphere while holding the global average temperature increase to the limit set by the Paris Agreement. However, a wide range of estimates for the remaining carbon budget has been reported, reducing the effectiveness of the remaining carbon budget as a means of setting emission reduction targets that are consistent with the Paris Agreement. Here we present a framework that enables us to track estimates of the remaining carbon budget and to understand how these estimates can improve over time as scientific knowledge advances. We propose that application of this framework may help to reconcile differences between estimates of the remaining carbon budget and may provide a basis for reducing uncertainty in the range of future estimates.
\end{abstract}

$\mathrm{S}$ ince the Fifth Assessment Report of the Intergovernmental Panel on Climate Change (IPCC $)^{1}$, the concept of a carbon budget has risen to prominence as a tool in guiding climate policy ${ }^{2}$. We here define the remaining carbon budget

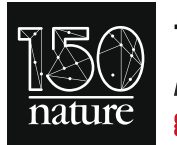

An 150 VERS OF NATURE Anniversary collection go.nature.com/nature150
$\mathrm{CO}_{2}$ emitted into the atmosphere by human activities adds to warming, and it does not matter whether this tonne of $\mathrm{CO}_{2}$ is emitted today, tomorrow or yesterday. This also implies that to limit temperature increase to any level, global $\mathrm{CO}_{2}$ emissions produced by human as the finite total amount of $\mathrm{CO}_{2}$ that can be emitted into the atmosphere by human activities while still holding global warming to a desired temperature limit. This is not to be confused with another concept, the historical carbon budget, which describes estimates of all major past and contemporary carbon fluxes in the Earth system ${ }^{3}$. The idea of a remaining carbon budget is grounded in well established climate science. A series of studies over the past decade has clarified and quantified why the rise in global average temperature increase is roughly proportional to the total cumulative amount of $\mathrm{CO}_{2}$ emissions produced by human activities since the industrial revolution ${ }^{4-13}$. This literature has allowed scientists to define the linear relationship between warming and cumulative $\mathrm{CO}_{2}$ emissions as the transient climate response to cumulative emissions of $\mathrm{CO}_{2}$ (TCRE). Once established, the appeal of this concept became immediately evident: the possibility that the response of an enormously complex system-such as the response of planet Earth to our emissions of $\mathrm{CO}_{2}-$ could potentially be reduced to a roughly linear relationship would allow scientists to infer clear and easy-to-communicate implications. However, additional processes that influence and are influenced by future warming, such as the thawing of permafrost, have recently been included in models that simulate the Earth system. These additional processes add uncertainty and may change our understanding of this linear relationship. Moreover, global warming is not driven by emissions of $\mathrm{CO}_{2}$ only. Other greenhouse gases (such as methane, fluorinated gases or nitrous oxide) and aerosols and their precursors (including soot or sulphur dioxide) affect global temperatures. Estimating the remaining carbon budget thus also implies making assumptions about these non- $\mathrm{CO}_{2}$ contributions. This further complicates the relationship between future $\mathrm{CO}_{2}$ emissions and global warming.

Carbon budgets nevertheless have become a powerful tool for communicating the challenges we face in aiming to hold warming to $1.5^{\circ} \mathrm{C}$ and to well below $2^{\circ} \mathrm{C}$ - the limits of global average temperature increase set out in the United Nations Paris Agreement ${ }^{14-18}$. First, every tonne of activities must be reduced to net-zero levels at some point in time and, on average, stay at net-zero levels thereafter. Furthermore, when aiming to limit warming to below a specific limit, a finite carbon budget also implies that the more we emit in the coming years, the faster emissions will have to decline thereafter to stay within the same budget-simple arithmetic. Finally, once net $\mathrm{CO}_{2}$ emissions are brought to zero, warming would stabilize but would not disappear or be reversed ${ }^{19-21}$. Any amount by which a carbon budget compatible with a desired temperature limit is missed or exceeded would thus have to be actively and permanently removed from the atmosphere in later years. This could be achieved through measures that result in net negative $\mathrm{CO}_{2}$ emissions, which come with their own technical and social complications ${ }^{22-27}$. Besides its role as a communication tool, the carbon budget concept also provides a way to exchange knowledge across disciplines. For example, such knowledge exchange is already happening for climate change mitigation requirements between the geoscience community and other disciplines that study climate change from a more societal angle 28,29 .

\section{Diversity that may confuse}

Unfortunately, all that glitters is not gold. Over the past five years, a plethora of studies have been published ${ }^{12,30-44}$ further exploring and estimating the size of carbon budgets while in some way accounting for non- $\mathrm{CO}_{2}$ climate forcing. These studies most often focus on requirements for holding warming to the internationally agreed $1.5^{\circ} \mathrm{C}$ or $2^{\circ} \mathrm{C}$ limits ${ }^{14-16}$. Although all studies aim to evaluate the same quantity, the use of different definitions and non- $\mathrm{CO}_{2}$ climate forcing assumptions, as well as methodological and model differences, have led to a wide variety of reported carbon budget estimates that aim to achieve temperature goals that are nominally the same (see Box 1 for an overview of carbon budget estimation approaches). This variation seems to have decreased instead of increased the broader understanding of 
the remaining carbon budget and has thus tempered the initial enthusiasm about its usefulness as a guide for policy making and target setting $^{45,46}$. This confusion is avoidable, however. Differences in remaining carbon budget estimates can be understood if a set of potential contributing factors are carefully taken into account.

Here we present a conceptual framework that allows one to track, understand, update and explain estimates of the remaining carbon budget over time. The framework's structure enables the assessment of individual contributing factors, including historical warming, the TCRE, the zero-emissions commitment and non- $\mathrm{CO}_{2}$ contributions to future warming. It integrates suggestions made in earlier literature $\mathrm{e}^{12,47}$ and is a generalization and extension of the framework used in ref. ${ }^{48}$.

\section{Remaining carbon budget framework}

As discussed, the remaining carbon budget can be defined as the remaining amount of $\mathrm{CO}_{2}$ emissions that can still be emitted while keeping the global average temperature increase due to human activities to below a specific temperature limit. The framework set out below applies to a situation in which one aims to limit peak (or maximum) warming and its associated impacts. It can, however, also be extended to apply to a situation where temperature rise has temporarily exceeded an intended temperature limit, often referred to as a temperature overshoot (see Supplementary Text 1).

We present in equation (1) an estimate of the remaining carbon budget $\left(B_{\text {lim }}\right)$ for a specific temperature change limit $\left(T_{\text {lim }}\right)$ as a function of five terms that represent aspects of the geophysical and coupled human-environment system (equation (1): the historical human-induced warming to date $\left(T_{\text {hist }}\right)$, the non- $\mathrm{CO}_{2}$ contribution to future temperature rise $\left(T_{\text {nonCO }}\right)$, the zero-emissions commitment $\left(T_{\mathrm{ZEC}}\right)$, the TCRE, and an adjustment term for sources of unrepresented Earth system feedback $\left(E_{\mathrm{Esfb}}\right)$. These terms are visualized in Fig. 1 and are described and discussed in turn below.

$$
B_{\text {lim }}=\left(T_{\text {lim }}-T_{\text {hist }}-T_{\text {nonCO }_{2}}-T_{\text {ZEC }}\right) / \mathrm{TCRE}-E_{\text {Esfb }}
$$

\section{Transient climate response to cumulative emissions}

Arguably the most central term to estimating the remaining carbon budget is the TCRE (in units of ${ }^{\circ} \mathrm{C}$ per gigatonne of carbon dioxide $\left(\mathrm{Gt} \mathrm{CO}_{2}\right)$; see equation (1). In essence, the remaining carbon budget is estimated by multiplying the remaining allowable warming with the inverse of the TCRE, where the magnitude of the remaining allowable warming is the result of various contributions shown in Fig. 1 and discussed below. The TCRE can be estimated from several lines of evidence, including the observational record ${ }^{10,12,49-51}, \mathrm{CO}_{2}$-only simulations ${ }^{10}$ and multi-gas simulations ${ }^{12,31,49-53}$ with Earth system models of varying complexity. In its latest assessment ${ }^{54}$, the IPCC reported the TCRE to fall within the range of $0.2-0.7^{\circ} \mathrm{C}$ per $1,000 \mathrm{Gt} \mathrm{CO}_{2}$ with a probability of at least $66 \%$. TCRE, and hence the linear proportionality of warming to cumulative emissions of $\mathrm{CO}_{2}$, has also been found to be robust up to about $7,300 \mathrm{Gt} \mathrm{CO}_{2}$ of cumulative emissions ${ }^{54,55}$ and probably more ${ }^{56}$. This domain of application easily spans the range of carbon budgets consistent with warming limits of $1.5^{\circ} \mathrm{C}$ and $2{ }^{\circ} \mathrm{C}$.

\section{Historical and maximum temperature increase}

After TCRE, the combined remaining allowable warming (represented by $\left.T_{\text {lim }}-T_{\text {hist }}-T_{\text {nonCO }_{2}}-T_{\mathrm{ZEC}}\right)$ is the next key determinant for estimating the remaining carbon budget. Its first term is the specific temperature limit of interest relative to preindustrial levels $\left(T_{\mathrm{lim}}\right.$, in units of ${ }^{\circ} \mathrm{C}$ ), and its second term represents the historical human-induced warming $\left(T_{\text {hist }}\right.$, in units of $\left.{ }^{\circ} \mathrm{C}\right)$; see equation (1). $T_{\text {hist }}$ is the amount of human-induced warming since preindustrial times until a more recent reference period, such as the 2006-2015 period.

The estimation of $T_{\text {hist }}$ is a central factor affecting the size of the remaining carbon budget, because it determines how far we currently are from policy-relevant temperature limits $\left(1.5^{\circ} \mathrm{C}\right.$ or $\left.2^{\circ} \mathrm{C}\right)$. The assessment of $T_{\text {hist }}$ should adequately isolate the human-induced warming signal from the effects of natural forcing and variability ${ }^{57,58}$.

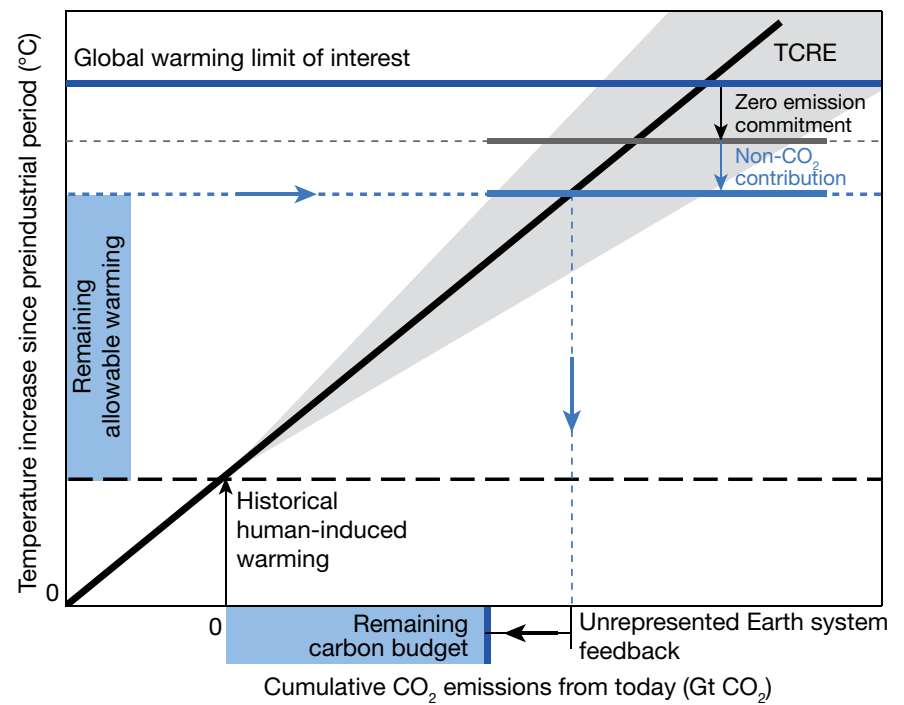

Fig. 1 | Schematic of factors contributing to the quantification of a remaining carbon budget. The schematic shows how the remaining carbon budget can be estimated from various independently assessable quantities, including the historical human-induced warming $T_{\text {hist }}$, the zero-emissions commitment $T_{\mathrm{ZEC}}$, the contribution of future non- $\mathrm{CO}_{2}$ warming (consistent with global net-zero $\mathrm{CO}_{2}$ emissions or otherwise) $T_{\text {nonCO }_{2}}$, the transient climate response to cumulative emissions of carbon (TCRE), and further correcting for unrepresented Earth system feedback $E_{\text {Esfb. }}$ The grey shading illustrates how uncertainty in TCRE propagates from the start point. Arrows and dashed lines are visual guides illustrating how the various factors combine to provide an estimate of the remaining carbon budget. Besides estimating the remaining carbon budget $B_{\text {lim }}$, the framework can also be applied to understand, decompose and discuss estimates of carbon budgets calculated by other methods. The relative sizes of the various contributions shown in this schematic are not to scale.

The same is true for $T_{\text {lim }}$, and if $T_{\text {lim }}$ is intended to represent an internationally agreed climate goal in line with the Paris Agreement it should do so by definition ${ }^{15}$. Two additional choices play an important role in determining or setting $T_{\text {hist }}$ and $T_{\text {lim }}$ : the choice of the preindustrial reference period and the temperature metric for determining global average temperature increase. Neither the preindustrial reference period nor the specific warming metric are explicitly defined by the Paris Agreement and recent literature has explored the implications and interpretations of this ambiguity ${ }^{34,35,59}$.

The 1850-1900 period is often used as a proxy for preindustrial levels because observational temperature records stretch back to the beginning of that period ${ }^{60}$, and key scientific reports that fed into the Paris Agreement also used this proxy ${ }^{1,59,61,62}$ (see Supplementary Text 2 for more details). Other periods have been suggested ${ }^{63-65}$, but ultimately the crux lies in that $T_{\text {hist }}$ and $T_{\text {lim }}$ should always be expressed relative to the same preindustrial reference period to avoid introducing erroneous changes to the remaining allowable warming and therewith the remaining carbon budget. Besides defining an appropriate preindustrial reference period, the choice of metric by which warming is estimated from that period is also important. Studies analysing climate model simulations or observational products can use different metrics to estimate global mean temperature change (see Supplementary Text 2). The impact of this metric choice has been highlighted recently with studies $^{34,59}$ showing that this choice can result in variations in the estimated global warming of the order of $10 \%$ (Supplementary Fig. 1), leading to a potential variation in remaining carbon budget estimates of more than 400 billion tonnes of $\mathrm{CO}_{2}$ (ref. ${ }^{59}$ ). The IPCC has typically specified carbon budgets based on global area-averaged change in surface air temperature $^{48,66}$. Other studies, however, have used different metrics and at times have even changed metrics between observations and projections (Supplementary Table 1, Fig. 2). This limits the comparability of these budget estimates ${ }^{59}$-a situation this new framework attempts to avoid. 


\section{Non- $\mathrm{CO}_{2}$ contribution to future warming}

Another term affecting the remaining allowable warming is the non- $\mathrm{CO}_{2}$ contribution to future global temperature rise $\left(T_{\text {nonCO }_{2}}\right.$, in units of ${ }^{\circ} \mathrm{C}$ ) (see equation (1) and Fig. 1). Current and future warming depends on both $\mathrm{CO}_{2}$-induced warming and warming due to non- $\mathrm{CO}_{2}$ forcing. Future non- $\mathrm{CO}_{2}$ warming might be considerable, given that reducing emissions of cooling sulphur dioxide causes warming ${ }^{67}$ and the knowledge that no obvious mitigation options have been identified that can completely eliminate several important sources of non- $\mathrm{CO}_{2}$ greenhouse gases ${ }^{68,69}$. To include $T_{\text {nonCO }}$ in the remaining carbon budget framework, the non- $\mathrm{CO}_{2}$ warming contribution between a recent reference period (for example, the same period as $T_{\text {hist }}$ ) and a specific time in the future has to be estimated. We suggest that this non- $\mathrm{CO}_{2}$ contribution to future temperature rise should be estimated from scenarios with an internally consistent evolution of greenhouse gases and other climate forcers ${ }^{36,70-74}$ and at the moment at which global $\mathrm{CO}_{2}$ emissions reach net zero ${ }^{48}$. Estimating the non- $\mathrm{CO}_{2}$ warming contribution at that moment in time reflects a situation in which global cumulative emissions of $\mathrm{CO}_{2}$ are effectively capped and hence allows us to directly inform the question of how much $\mathrm{CO}_{2}$ can be emitted while keeping warming to a given temperature level. If non- $\mathrm{CO}_{2}$ warming were to be estimated at other moments in time, its usefulness for informing mitigation requirements would potentially be strongly reduced.

Besides the future evolution of non- $\mathrm{CO}_{2}$ emissions, the non- $\mathrm{CO}_{2}$ warming contribution also depends on estimates of the corresponding radiative forcing, including potential changes in surface albedo ${ }^{43}$. Non- $\mathrm{CO}_{2}$ forcing and warming can be estimated with the help of simple climate models ${ }^{43,75,76}$, inferred from more complex climate model runs $^{77}$, or taken from the literature ${ }^{37,48}$. Importantly, non- $\mathrm{CO}_{2}$ emissions would continue to affect warming levels after the time when net $\mathrm{CO}_{2}$ reaches zero, which creates uncertainty in methods that estimate budgets by integrating changes over time and after an overshoot (for example, see refs ${ }^{36,43}$ and Box 1). These uncertainties are reduced in the framework proposed in this Perspective by focusing on the time of reaching net-zero $\mathrm{CO}_{2}$ emissions and by considering internally consistent non- $\mathrm{CO}_{2}$ emissions. Under these assumptions, non- $\mathrm{CO}_{2}$ emissions are projected to result in a constant or declining forcing and warming after the time of net-zero $\mathrm{CO}_{2}\left(\right.$ refs $\left.^{48,73}\right)$. However, if under alternative assumptions one would project non- $\mathrm{CO}_{2}$ warming to continue to increase irrespective of the level of $\mathrm{CO}_{2}$ emissions ${ }^{78}$, this further increase should also be accounted for within $T_{\text {nonCO }}$ because it would add to future peak warming.

\section{Zero-emissions commitment}

The zero-emissions commitment, $T_{\text {ZEC }}$ (in units of ${ }^{\circ} \mathrm{C}$ ) is the next term in the remaining carbon budget framework represented by equation (1). $T_{\mathrm{ZEC}}$ is defined as the additional contribution to peak warming that is still to be expected after a complete cessation of $\mathrm{CO}_{2}$ emissions $^{79,80}$, and hence provides a correction term for the instantaneous linearity postulated by the concept of the TCRE. $T_{\text {ZEC }}$ can be positive, negative or zero. For estimates of the remaining carbon budget, the $T_{\mathrm{ZEC}}$ when $\mathrm{CO}_{2}$ emissions approach net-zero levels is of particular interest. In more general terms, this could also be formulated as an assessment of the lag in $\mathrm{CO}_{2}$-induced warming at current and declining emissions rates ${ }^{50,79}$. When $T_{\mathrm{ZEC}}$ is positive, not all warming will have been experienced by the time global $\mathrm{CO}_{2}$ emissions reach net zero. The estimated additional warming would hence also have to be reduced from the allowable remaining temperature increase. At present, $T_{\mathrm{ZEC}}$ is frequently neglected in carbon budget studies (see Supplementary Table 1, with exceptions only hypothesizing the effect of its contribu$\operatorname{tion}^{37}$ ) and is hence implicitly assumed to be zero or negative. Several studies suggest, however, that there might be a smaller ${ }^{79-82}$ or larger ${ }^{83,84}$ lag between the time when $\mathrm{CO}_{2}$ emissions have ceased and the time of maximum warming caused by those emissions. Instead of being accounted for as a separate term, the $T_{\mathrm{ZEC}}$ could also be integrated within the assessment of TCRE, although a dedicated methodological framework to do so is currently lacking.

\section{Box 1 Frequently used carbon budget
definitions}

Studies differ in how they define the carbon budget, and these differences affect the accuracy, size and usefulness of reported estimates. This box provides an overview of five ways in which carbon budgets can be defined, and highlights some of their strengths and weaknesses as well as how they link to the remaining carbon budget framework introduced here.

Peak or maximum temperature budgets are defined as the cumulative amount of net $\mathrm{CO}_{2}$ emissions that would hold maximum warming to a specific temperature limit. In most cases, peak warming roughly coincides with the timing of a pathway reaching net-zero $\mathrm{CO}_{2}$ emissions, and peak temperature budgets are thus directly compatible with the framework proposed in this paper. They also provide a direct estimate of the amount of $\mathrm{CO}_{2}$ emissions that is consistent with achieving international temperature goals ${ }^{48}$.

Threshold return budgets are defined as the cumulative amount of net $\mathrm{CO}_{2}$ emissions until a specific level of warming is reached, yet only after having temporarily exceeded that level by a certain amount and during a certain period of time earlier ${ }^{36,47}$. By definition, they include a period of global net removal of $\mathrm{CO}_{2}$ and hence must account for potential additional nonlinearities in the Earth system response ${ }^{105}$. Supplementary Text 1 clarifies how the framework presented here can be adjusted to suit this definition.

Threshold exceedance budgets are defined as the cumulative amount of net $\mathrm{CO}_{2}$ emissions until the time at which temperature projections for a given pathway exceed a temperature threshold of interest ${ }^{37}$. This method has been often applied by studies that estimate carbon budgets from a limited set of simulations of complex Earth system models ${ }^{10,30,32,54}$. They do not provide a direct estimate of the amount of $\mathrm{CO}_{2}$ emission that is consistent with achieving international temperature goals, but can still be discussed and understood within the framework presented in this Perspective, for example, by explicitly clarifying assumptions regarding historical warming and non- $\mathrm{CO}_{2}$ warming at the time the temperature threshold is exceeded, and assumed values for $T_{\text {ZEC }}$ and TCRE.

Threshold avoidance budgets are derived from emissions pathways that avoid crossing a temperature threshold of interest ${ }^{37}$. Their main drawback is that their definition leaves a lot of room for interpretation and variation. First, in contrast to previous budget definitions, no unambiguous point in time is available for threshold avoidance budgets until such time as net $\mathrm{CO}_{2}$ emissions are summed, thus requiring additional assumptions ${ }^{37,39}$. Second, any scenario that limits warming below a threshold of interest (whether slightly or by a much larger margin) could be included in a threshold avoidance budget estimate ${ }^{71}$. This makes these estimates imprecise, extremely variable and difficult to compare across studies. However, even here the framework presented in this Perspective can help to structure discussions.

Finally, some studies report descriptive statistics of emissions pathways, such as cumulative $\mathrm{CO}_{2}$ emissions until 2050 or 2100 , instead of estimates of remaining carbon budgets. These statistics are not directly selected on the basis of their temperature outcome $^{36,71}$ and should not be interpreted as geophysical carbon budget requirements.

\section{Unrepresented sources of Earth system feedback}

Finally, reductions in emissions due to unrepresented Earth system feedback mechanisms $\left(E_{\mathrm{Esfb}}\right.$, in units of $\left.\mathrm{Gt}_{\mathrm{CO}}\right)$, are the last term in the proposed remaining carbon budget framework (equation (1)). Any Earth system feedback that is not yet incorporated in estimates of the TCRE or that would reduce the applicability of TCRE should be assessed, and accounted for and communicated as part of $E_{\mathrm{Esfb}}$. 
Latest IPCC assessment of remaining carbon budgets using SAT estimate of global warming

Ref. 48

Ref. 48
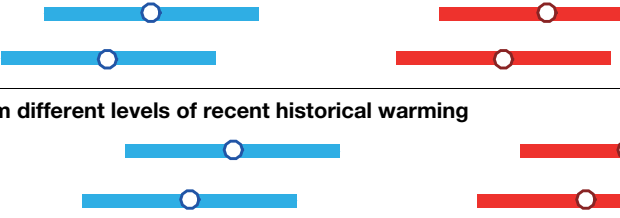

Estimates starting from different levels of recent historical warming

Ref. 48

Ref. 48

Ref. 32

Ref. 39

Ref. 30

○

Ref. 31

Estimates starting from preindustrial period
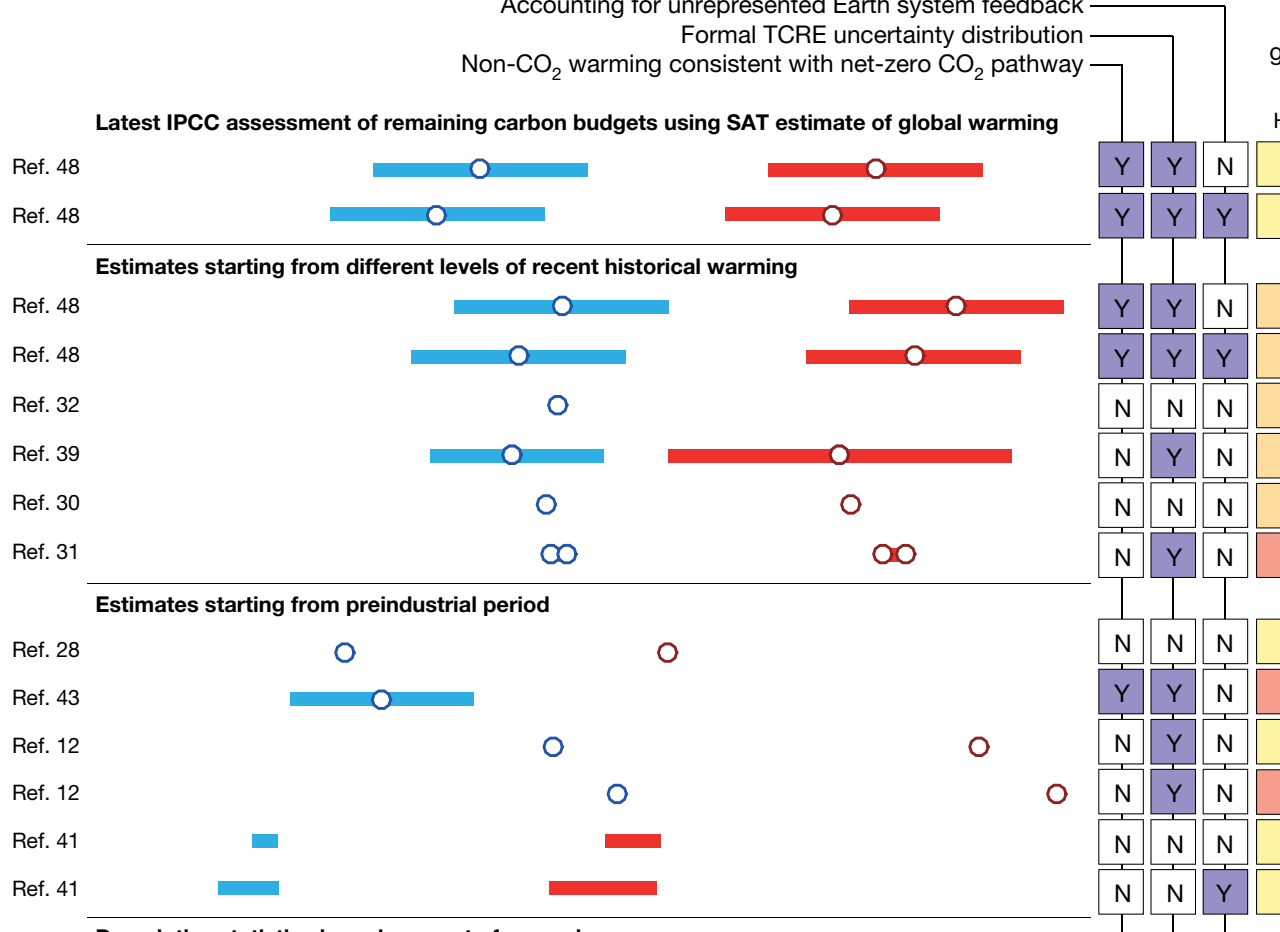

Applied

global warming

definition

History Projection

\begin{tabular}{|c|c|c|c|c|c|}
\hline & & & History & rojection & \\
\hline Y & Y & $\mathrm{N}$ & SAT & SAT & \\
\hline Y & Y & Y & SAT & SAT & $\begin{array}{l}100 \mathrm{Gt} \mathrm{CO}_{2} \text { permafrost } \\
\text { thawing reduction until } 2100\end{array}$ \\
\hline Y & $\mathrm{Y}$ & $\mathrm{N}$ & BT & SAT & \\
\hline Y & $\mathrm{Y}$ & Y & BT & SAT & $\begin{array}{l}100 \mathrm{Gt} \mathrm{CO}_{2} \text { permafrost } \\
\text { thawing reduction until } 2100\end{array}$ \\
\hline $\mathrm{N}$ & $\mathrm{N}$ & $\mathrm{N}$ & BT & SAT & $\begin{array}{l}58 \text { CMIP5 simulations with } \\
\text { observational constraints }\end{array}$ \\
\hline $\mathrm{N}$ & Y & $\mathrm{N}$ & BT & SAT & $\begin{array}{l}\text { TCRE distribution with } \\
\text { observational constraints }\end{array}$ \\
\hline $\mathrm{N}$ & $\mathrm{N}$ & $\mathrm{N}$ & BT & SAT & Based on 20 CMIP5 models \\
\hline $\mathrm{N}$ & $\mathrm{Y}$ & $\mathrm{N}$ & BT & BT & $\begin{array}{l}\text { TCRE distribution with } \\
\text { observational constraints }\end{array}$ \\
\hline $\mathrm{N}$ & $\mathrm{N}$ & $\mathrm{N}$ & SAT & SAT & TEB based on 20 CMIP5 models \\
\hline Y & Y & $\mathrm{N}$ & BT & BT & Strong aerosol unmasking \\
\hline $\mathrm{N}$ & $\mathrm{Y}$ & $\mathrm{N}$ & SAT & SAT & $\begin{array}{l}\text { Based on CMIP5 Earth } \\
\text { system models }\end{array}$ \\
\hline $\mathrm{N}$ & Y & $\mathrm{N}$ & BT & BT & Based on observations \\
\hline $\mathrm{N}$ & $\mathrm{N}$ & $\mathrm{N}$ & SAT & SAT & $\begin{array}{l}\text { TEB variation across } \\
\text { four RCPs }\end{array}$ \\
\hline $\mathrm{N}$ & $\mathrm{N}$ & Y & SAT & SAT & TEB including permafrost thawing \\
\hline Y & Y & N & BT & SAT & $\begin{array}{l}\text { Peak TAB; TCRE with observational } \\
\text { constraints; warming }<1.5^{\circ} \mathrm{C} \text { or }<2{ }^{\circ} \mathrm{C}\end{array}$ \\
\hline Y & $\mathrm{Y}$ & $\mathrm{N}$ & BT & SAT & $\begin{array}{l}\text { TCRE with observational constraints; } \\
\text { warming }<1.5^{\circ} \mathrm{C}\end{array}$ \\
\hline
\end{tabular}

Descriptive statistics based on a set of scenarios

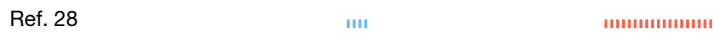

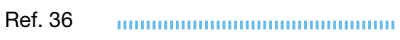

Remaining carbon budget from 2018 onward $\left(\mathrm{Gt} \mathrm{CO}_{2}\right)$

Fig. 2 | Comparison of recent remaining carbon budget estimates for limiting global warming to $1.5^{\circ} \mathrm{C}$ (blue) and to $2^{\circ} \mathrm{C}($ red) relative to preindustrial levels, and overview of factors affecting their variation. Estimates are shown for a 50\% probability of limiting warming to the indicated temperature levels (additional estimates for a $66 \%$ probability are provided in Supplementary Table 2). Several studies do not report formal probabilities, but report the frequency distribution across model simulations instead. The latter estimates are marked $\mathrm{N}$ in the 'Formal TCRE uncertainty distribution' column. Estimates shown with dashed lines indicate carbon budget estimates with an imprecise level of implied global warming, for example, because they were reported for a radiative forcing target instead. TEB means threshold exceedance budget ${ }^{37}$; TAB means threshold avoidance budget ${ }^{37}$ (see Box 1 ). Data are taken from the

These feedback processes have typically been related to permafrost thawing ${ }^{40-42,85}$ and the associated long-term release of $\mathrm{CO}_{2}$ and $\mathrm{CH}_{4}$. However, other Earth system feedback sources that can affect remaining carbon budgets have been identified ${ }^{42}$, including changes in vegetation $\mathrm{CO}_{2}$ uptake linked to nitrogen availability ${ }^{86-88}$. If unrepresented feedback results in a direct $\mathrm{CO}_{2}$ emission from an ecosystem, the translation to the $E_{\mathrm{Esfb}}$ term is direct. However, because of the diverse nature of Earth system feedback ${ }^{42}$, accounting for it through an adjustment in $\mathrm{CO}_{2}$ emissions is not always straightforward. For example, if a feedback system results in the release of other greenhouse gases or affects the Earth system through changes in surface albedo, clouds or fire regimes, for example, its contribution needs to be translated into an equivalent $\mathrm{CO}_{2}$ correction term (see refs ${ }^{89,90}$ for example). Because most Earth system feedback is either sensitive to rising $\mathrm{CO}_{2}$ or to variations in climate parameters, it is expected that these contributions are scenario-dependent, nonlinear, and in some cases realized over longer timescales only ${ }^{40,41,85,91-98}$. This adds to the complexity of the translation into a $\mathrm{CO}_{2}$-equivalent correction term, and makes $E_{\mathrm{Esfb}}$ an uncertain contribution. $E_{\mathrm{Esfb}}$ could be estimated either for the time at which global net $\mathrm{CO}_{2}$ emissions become zero or until the end of the century or beyond, assuming anthropogenic $\mathrm{CO}_{2}$ emissions are kept at net-zero levels but feedback mechanisms continue to change over
IPCC Special Report on Global Warming of $1.5^{\circ} \mathrm{C}$ (ref. ${ }^{48}$ ), ref. ${ }^{39}$ (with values for $1.5^{\circ} \mathrm{C}$ based on our own calculations using the same method), the IPCC Fifth Assessment Report (ref. ${ }^{28}$ ) and refs ${ }^{12,30-32,36,41,43}$. The latest IPCC assessment of the remaining carbon budget ${ }^{48}$ assumes $0.97^{\circ} \mathrm{C}$ of historical warming until 2006-2015, whereas other estimates assume either higher or lower warming for that period (Supplementary Table 1). The background and values for all studies are provided in Supplementary Tables 1 and 2. The assumptions made for each study are coloured (righthand side of figure) for ease of visual grouping: N, no; Y, yes; SAT, global near-surface air temperatures; BT, blended temperatures (surface air temperature over land and sea-ice regions combined with sea surface temperature over open ocean); RCP, Representative Concentration Pathway; CMIP5, Phase 5 of the Coupled Model Intercomparison Project.

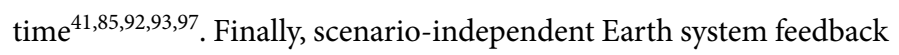
that scales linearly with global average temperature increase could also be incorporated by adjusting the TCRE, as long as it is not doublecounted in both $E_{\mathrm{Esfb}}$ and TCRE.

\section{Tracking and explaining scientific progress}

We are of the opinion that through conscientious and rigorous application of the framework we propose in this Perspective, much of the confusion surrounding the size and variation of remaining carbon budget estimates can be avoided. Our proposed framework allows scientists to identify, understand and track how the progression of science on multiple fronts can affect budget estimates. It also allows us to identify and discuss key uncertainties and choices related to each respective term (Table 1). Together, these two improvements can contribute to a more constructive and informed discussion of the topic, and better communication across the various disciplines and communities that research, quantify and apply estimates of the remaining carbon budget.

The road from the geosciences to climate policy is long and winding. However, carbon budgets provide one of the simplest and most transparent means of connecting geophysical limits imposed by the Earth system to implications for climate policy. For example, they provide 
Table 1 | Key choices or uncertainties of terms affecting estimates of the remaining carbon budget

\begin{tabular}{|c|c|c|c|c|}
\hline Term & Symbol & Key choices or uncertainties & Type & Level of understanding \\
\hline Temperature limit & $T_{\lim }$ & $\begin{array}{l}\text { Choice of temperature metrics used to express global warming, } \\
\text { choice of preindustrial reference period, and consistency with global } \\
\text { climate goals }\end{array}$ & Choice & Medium to high \\
\hline $\begin{array}{l}\text { Historical human-induced } \\
\text { warming }\end{array}$ & $T_{\text {hist }}$ & $\begin{array}{l}\text { Choice of temperature metrics used to express global warming, } \\
\text { choice of preindustrial reference period, and consistency with global } \\
\text { climate goals }\end{array}$ & Choice & Medium to high \\
\hline $\begin{array}{l}\text { Historical human-induced } \\
\text { warming }\end{array}$ & $T_{\text {hist }}$ & $\begin{array}{l}\text { Incomplete coverage in observational data sets, and methods to } \\
\text { estimate human-induced component }\end{array}$ & Uncertainty & Medium to high \\
\hline $\begin{array}{l}\text { Non- } \mathrm{CO}_{2} \text { contribution to } \\
\text { future global warming }\end{array}$ & $T_{\text {nonCO }_{2}}$ & $\begin{array}{l}\text { The level of different non- } \mathrm{CO}_{2} \text { emissions that are consistent with } \\
\text { global net-zero } \mathrm{CO}_{2} \text { emissions, which depends on policy choices but } \\
\text { also on uncertain success of their implementation }\end{array}$ & Choice and uncertainty & Medium \\
\hline $\begin{array}{l}\text { Non- } \mathrm{CO}_{2} \text { contribution to } \\
\text { future global warming }\end{array}$ & $T_{\text {nonCO }_{2}}$ & $\begin{array}{l}\text { Climate response to non- } \mathrm{CO}_{2} \text { forcers, particularly in the level of } \\
\text { aerosol recovery and temperature reduction from lower methane } \\
\text { emissions }\end{array}$ & Uncertainty & Low to medium \\
\hline Zero-emissions commitment & $T_{\text {ZEC }}$ & $\begin{array}{l}\text { Sign and magnitude of zero-emission commitment at decadal time } \\
\text { scales for current and near-zero annual } \mathrm{CO}_{2} \text { emissions }\end{array}$ & Uncertainty & Low \\
\hline $\begin{array}{l}\text { Transient climate response to } \\
\text { cumulative emissions of } \mathrm{CO}_{2}\end{array}$ & TCRE & $\begin{array}{l}\text { Distribution of TCRE uncertainty, linearity of TCRE for increasing and } \\
\text { stabilizing cumulative } \mathrm{CO}_{2} \text { emissions, and impact of temperature } \\
\text { metrics on TCRE estimate }\end{array}$ & Uncertainty & Low to medium \\
\hline $\begin{array}{l}\text { Transient climate response to } \\
\text { cumulative emissions of } \mathrm{CO}_{2}\end{array}$ & TCRE & $\begin{array}{l}\text { When extended beyond peak warming (Supplementary Text } 1 \text { ), } \\
\text { uncertainty about linearity, value and distribution of TCRE for } \\
\text { decreasing cumulative } \mathrm{CO}_{2} \text { emissions }\end{array}$ & Uncertainty & Low \\
\hline $\begin{array}{l}\text { Unrepresented Earth system } \\
\text { feedback mechanisms }\end{array}$ & $E_{\text {Esfb }}$ & $\begin{array}{l}\text { Timescale and magnitude of permafrost thawing and methane } \\
\text { release from wetlands and their representation in Earth system } \\
\text { models, as well as other potential types of feedback }\end{array}$ & Uncertainty & Very low \\
\hline
\end{tabular}

the geophysical foundation for setting global net-zero targets ${ }^{6,99}$, which have recently been picked up by policy scholars as being potentially more effective in guiding policy towards a more actionable climate change mitigation goal ${ }^{100}$. When combined with models that simulate possible transformations to a low-carbon society ${ }^{101}$, they can also help inform other, more specific, climate change mitigation targets.

Nevertheless, adequately characterizing and communicating the uncertainties that surround carbon budget estimates is a challenge that will remain. These uncertainties are not unfathomable, however, and language exists to describe the nature of the various uncertainty contributions $^{102}$ (Table 1, Fig. 2). In some cases, uncertainties exist because of our imprecise knowledge of certain processes or lack of precise measurements. This uncertainty is applicable to all terms in our framework except for $T_{\mathrm{lim}}$, and will only gradually be reduced over time. In other cases, terms are not used consistently throughout the literature, resulting in confusion and inconsistency between carbon budget estimates (Table 1, Supplementary Table 1, Fig. 2). This is the case for the choice of global temperature metric or for the time period over which remaining carbon budgets are computed. For increased comparability and flexibility, it would be useful if global surface air temperature values were routinely estimated for observational products and if climate model projections were to report both metrics. Some uncertainties represent policy choices ${ }^{44}$. An example of such uncertainty is the estimate of the non- $\mathrm{CO}_{2}$ emissions contribution to future warming. Future non- $\mathrm{CO}_{2}$ emissions depend on future socio-economic developments and deployment of mitigation measures, and these are influenced by policy and societal choices today, for example, regarding how much the emission of non- $\mathrm{CO}_{2}$ greenhouse gases is penalized or which sectors are targeted when promoting innovation for climate change mitigation. These policy-driven uncertainties and ambiguities can be understood, quantified and explained using a scenario-based approach. For sources of Earth system feedback that are not fully represented in models, a quantification of their impact remains difficult. Expert judgment can be applied in this case to provide an estimate of its importance.

The overview of assumptions made in carbon budget studies (Fig. 2 and Supplementary Tables 1 and 2) can already provide a first step in understanding the relative differences between estimates. For example, except for the most recent IPCC report ${ }^{48}$, none of the estimates available in the literature simultaneously apply consistent global warming metrics for historical and projected temperatures together with a non- $\mathrm{CO}_{2}$ warming contribution reflecting a future that is in line with the Paris Agreement (Fig. 2, Supplementary Tables 1 and 2). Several estimates also infer the chance of limiting warming to $1.5^{\circ} \mathrm{C}$ from ad hoc frequency distributions of model results, instead of from a formal representation of the uncertainty in TCRE. In addition, studies typically do not include all currently identified Earth system feedback, although the impact of some has been described in dedicated studies ${ }^{40-42,85}$.

Comparing estimates that are the same in all but their inclusion of some of the unrepresented Earth system feedback mechanisms (from refs ${ }^{41,48}$ ) suggests that the inclusion of additional Earth system feedback could consistently reduce estimates of the remaining carbon budget-something to bear in mind when future studies that use the latest generation of Earth system models become available ${ }^{103}$. A further insight is that estimates that apply temperature metrics other than global surface air temperatures (Fig. 2 and Supplementary Text 2) consistently suggest remaining carbon budgets that are larger than estimates that use surface air temperature only. The reasons underlying this perceived shift are well understood (see Supplementary Text 2) and can be identified as an artefact of a methodological choice. To be sure, although estimates using temperature metrics other than global averaged surface air temperature usually suggest a larger remaining carbon budget, they also come with clear climate change consequences: a relatively hotter Earth, inconsistent with the long-term temperature goal of the Paris Agreement ${ }^{59}$. A sound rationale therefore needs to accompany the choice of temperature metric. We strongly recommend using global average surface air temperature as the temperature metric because it is computed from invariable fields across models, model runs and over time. More detailed comparisons between published estimates of remaining carbon budgets are complicated or impossible at this stage because the quantifications of the various contributing factors by the original studies are lacking. Hence, we suggest that future studies should provide a quantitative discussion of assumptions and factors contributing to their remaining carbon budget estimates 


\section{Box2}

\section{An application of the framework to determine the remaining carbon budget}

Using the framework (equation (1)), remaining carbon budgets in line with limiting warming to $1.5^{\circ} \mathrm{C}$ or to $2^{\circ} \mathrm{C}$ can be estimated by drawing on information available in the literature. We now provide an example of how this could be done, starting from the assessment carried out in the context of the IPCC Special Report on Global Warming of $1.5^{\circ} \mathrm{C}$ (ref. ${ }^{48}$ ).

The temperature metric is defined as follows: global warming is estimated as the global area-averaged surface air temperature change for historical warming and future projections so that $T_{\lim }$ is defined by a single consistent metric.

The preindustrial reference period is 1850-1900, as a proxy for preindustrial levels.

$T_{\text {hist }}$ is taken to be $0.97^{\circ} \mathrm{C}$ until $2006-2015$ since $1850-1900$. It is derived by correcting the estimate of a global dataset ${ }^{60,106}$ using the ratio between global surface air temperature and blended temperatures (surface air temperature over land and sea-ice regions combined with sea surface temperature over open ocean) based on incomplete geographical coverage, as informed by models. This level of warming is attributed to climate forcing that is caused by human activities and hence accounts for the influence of natural (internal and natural forced) variability of the climate.

$T_{\text {nonco }}$ is estimated from integrated pathways that include all climate forcing caused by human activities and derived at the time that global total $\mathrm{CO}_{2}$ emissions reach net-zero levels ${ }^{73,74}$. It is estimated ${ }^{75,76}$ to be about $0.1^{\circ} \mathrm{C}\left(0-0.2^{\circ} \mathrm{C}, 90 \%\right.$ range $)$ in scenarios that reach net-zero $\mathrm{CO}_{2}$ and limit warming to $1.5^{\circ} \mathrm{C}$ and to be about $0.2^{\circ} \mathrm{C}\left(0.1-0.4^{\circ} \mathrm{C}, 90 \%\right.$ range $)$ in scenarios limiting warming to $2^{\circ} \mathrm{C}$.

$T_{\text {ZEC }}$ is assumed to be zero or negative, and thus not to affect the remaining allowable warming.

The remaining allowable warming starting from the recent 20062015 period is hence about $0.4^{\circ} \mathrm{C}$ and $0.8^{\circ} \mathrm{C}$ for global temperature increase limits of $1.5^{\circ} \mathrm{C}$ and $2^{\circ} \mathrm{C}$, respectively.

TCRE is assumed to be normally distributed ${ }^{66}$ with a $1 \sigma$ range of $0.2-0.7^{\circ} \mathrm{C}$ per $1,000 \mathrm{Gt} \mathrm{CO}_{2}$.

$E_{\text {Esfb }}$ is estimated based on literature that explicitly quantifies the effect of permafrost thawing on additional $\mathrm{CO}_{2}$ release $40,41,85,93$ and that translates the effect of other unrepresented feedback into a $\mathrm{CO}_{2}$-equivalent correction ${ }^{42}$. It is estimated to reduce the

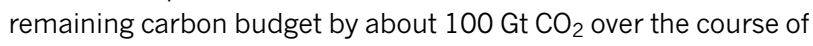
the twenty-first century, but this estimate has very low confidence attached to it (Table 1).

The combination of all terms in the framework presented here, and subtracting $290 \mathrm{Gt} \mathrm{CO}_{2}$ for global $\mathrm{CO}_{2}$ emissions since 2011 , results in a remaining carbon budget $B_{\text {lim }}$ of $480 \mathrm{Gt} \mathrm{CO}_{2}$ for a $50 \%$ probability of limiting global warming to $1.5^{\circ} \mathrm{C}$ (and with a $B_{\lim }$ of 740 and $320 \mathrm{Gt} \mathrm{CO}_{2}$ for $33 \%$ and $66 \%$ probabilities, respectively). For a $2{ }^{\circ} \mathrm{C}$ limit, $B_{\lim }$ amounts to $1,400 \mathrm{Gt} \mathrm{CO}_{2}$ for a $50 \%$ probability (and 1,930 or $1,070 \mathrm{Gt} \mathrm{CO}_{2}$ for a $33 \%$ or $66 \%$ probability, respectively). In the IPCC report ${ }^{48}$, reported numbers are $100 \mathrm{Gt} \mathrm{CO}_{2}$ larger because $E_{\mathrm{Esfb}}$ is reported separately. In addition, the impact of varying levels of success in reducing non- $\mathrm{CO}_{2}$ emissions can be estimated from the variation in $T_{\text {non } \mathrm{C}_{2}}$, suggesting a variation of about $\pm 250 \mathrm{Gt} \mathrm{CO}_{2}$ for the remaining carbon budget for a $1.5^{\circ} \mathrm{C}$ limit and -500 to $+250 \mathrm{Gt} \mathrm{CO}_{2}$ for a $2^{\circ} \mathrm{C}$ limit.

(Supplementary Text 3), without which it is often virtually impossible to determine them later.

In the future, this framework could play a part in contextualizing new estimates, even if such estimates are obtained using alternative methods. In addition, this framework can be used in combination with expert judgment to anticipate potential changes in the remaining carbon budget. Finally, application of the framework presented here also allows us to make a more independent assessment of remaining carbon budgets by drawing on multiple lines of evidence. A simplified version of this framework has also already been applied in ref. ${ }^{48}$ (see Box 2).

\section{Towards more robust carbon budget estimates}

Decomposing the remaining carbon budget into its contributing factors also allows one to identify a set of promising avenues for future research. An area of research that could advance this field is a closer look at TCRE. Future research is anticipated to narrow the range of best estimates of TCRE as well as to clarify the shape of the uncertainty distribution surrounding this value, the influence of a potential lag of $\mathrm{CO}_{2}$ warming on estimating TCRE, and the validity of the TCRE concept for annual emission rates approaching net zero or during episodes of global net $\mathrm{CO}_{2}$ removal. For example, at present there are no studies dedicated to explicit analysis of the uncertainty distribution surrounding TCRE, resulting in limited evidence to support the choice of a particular formal distribution (be it normal, lognormal, or otherwise $^{10,31,54}$ ) when estimating the remaining carbon budget (see Fig. 2 and Supplementary Table 1).

Another promising area of research is the study of the interdependence between factors and their uncertainties, for example, between uncertainties in $T_{\text {hist }}$ and $T_{\text {nonCO }}$. This could be pursued through the development of methods that allow robust estimates of recent levels of human-induced warming and allow us to link them to internally consistent projections of future non- $\mathrm{CO}_{2}$ warming. For example, methodological developments with reduced-complexity climate models could be useful ${ }^{57,75,104}$, because such models can flexibly and promptly incorporate most up-to-date observations and forcing estimates. This also ties into a larger question of trying to understand the overall, combined uncertainties affecting remaining carbon budgets. At present, each factor of the presented framework comes with its own uncertainties, and a method of formally combining these uncertainties is lacking.

Finally, an important uncertainty in determining the remaining carbon budget continues to be the quantification of uncertain and ill-constrained Earth system feedback processes that feed into the assessment of TCRE or $E_{\mathrm{Esfb}}$. Besides affecting carbon budgets that are consistent with limiting maximum warming to a specific temperature threshold, such feedback could help to inform the risks that would be incurred by exhausting and exceeding a specific carbon budget and temperature limit, and attempting to return warming afterwards to lower levels through global net $\mathrm{CO}_{2}$ removal (see the definition of the threshold return budget in Box 1). Challenges here lie in covering the full range of responses of these highly uncertain components, including high-risk, low-probability outcomes.

Advancements in any of these areas would improve our understanding of carbon budget estimates, and would be invaluable in the ongoing assessment of carbon budgets for the forthcoming Sixth Assessment Report of the IPCC. A systematic understanding of remaining carbon budget estimates is possible if studies improve their reporting. We recommend that future studies estimating the remaining carbon budget report the factors considered within this framework (see Supplementary Text 3 for a checklist): the surface temperature measure and historic warming used, what is assumed for TCRE, and how non- $\mathrm{CO}_{2}$ warming and Earth system feedback sources are accounted for. A systematic understanding of remaining carbon budget estimates and how they could evolve as science advances will be essential for effective target setting and for communicating the challenges of climate change mitigation.

\section{Online content}

Any Methods, additional references, Nature Research reporting summaries, source data, statements of data availability and associated accession codes are available in the online version of the paper at https://doi.org/10.1038/s41586-019-1368-z. 
Received: 27 October 2018; Accepted: 16 May 2019;

Published online 17 July 2019.

1. Intergovernmental Panel on Climate Change (IPCC) Climate Change 2013: The Physical Science Basis. Contribution of Working Group I to the Fifth Assessment Report of the Intergovernmental Panel on Climate Change (Cambridge Univ. Press, 2013).

2. Messner, D., Schellnhuber, J., Rahmstorf, S. \& Klingenfeld, D. The budget approach: a framework for a global transformation toward a low-carbon economy. J. Renew. Sustain. Energy 2, 031003 (2010).

3. Le Quéré, C. et al. Global carbon budget 2017. Earth Syst. Sci. Data 10, 405-448 (2018).

4. Zickfeld, K., Eby, M., Matthews, H. D. \& Weaver, A. J. Setting cumulative emissions targets to reduce the risk of dangerous climate change. Proc. Natl Acad. Sci. USA 106, 16129-16134 (2009)

5. Matthews, H. D., Gillett, N. P., Stott, P. A. \& Zickfeld, K. The proportionality of global warming to cumulative carbon emissions. Nature $\mathbf{4 5 9}, \mathbf{8 2 9 - 8 3 2}$ (2009).

6. Matthews, H. D. \& Caldeira, K. Stabilizing climate requires near-zero emissions. Geophys. Res. Lett. 35, https://doi.org/10.1029/2007GL032388 (2008). This was the first paper to highlight the importance of global net-zero $\mathrm{CO}_{2}$ emissions for limiting global warming.

7. Meinshausen, M. et al. Greenhouse-gas emission targets for limiting global warming to $2^{\circ} \mathrm{C}$. Nature $458,1158-1162$ (2009).

This seminal study reports carbon budgets up to the recent past and enabled the broad uptake of the carbon budget concept in climate policy discussions by linking it to the amount of carbon available in proven economically recoverable oil, gas and coal reserves.

8. Allen, M. R. et al. Warming caused by cumulative carbon emissions towards the trillionth tonne. Nature 458, 1163-1166 (2009).

9. MacDougall, A. H. \& Friedlingstein, P. The origin and limits of the near proportionality between climate warming and cumulative $\mathrm{CO}_{2}$ emissions. J. Clim. 28, 4217-4230 (2015).

This paper provides a decomposition of the various factors contributing to the near-linear proportionality underlying TCRE.

10. Gillett, N. P., Arora, V. K., Matthews, D. \& Allen, M. R. Constraining the ratio of global warming to cumulative $\mathrm{CO}_{2}$ emissions using $\mathrm{CMIP5}$ simulations. J. Clim. 26, 6844-6858 (2013). This study discusses the shape and observational constraints of the TCRE.

11. Zickfeld, K. et al. Long-term climate change commitment and reversibility: an EMIC intercomparison. J. Clim. 26, 5782-5809 (2013).

This multi-model study quantifies the warming commitment after a cessation of $\mathrm{CO}_{2}$ emissions.

12. Matthews, H. D. et al. Estimating carbon budgets for ambitious climate targets. Curr. Clim. Change Rep. 3, 69-77 (2017).

13. Williams, R. G., Goodwin, P., Roussenov, V. M. \& Bopp, L. A framework to understand the transient climate response to emissions. Environ. Res. Lett. 11 015003 (2016).

14. The United Nations Framework Convention on Climate Change (UNFCCC) Paris Agreement https://unfccc.int/sites/default/files/english_paris_ agreement.pdf (UNFCCC, 2015).

15. Rogelj, J., Schleussner, C.-F., \& Hare, W. Getting it right matters: temperature goal interpretations in geoscience research. Geophys. Res. Lett. 44, 10662-610665 (2017)

16. Schleussner, C.-F. et al. Science and policy characteristics of the Paris Agreement temperature goal. Nat. Clim. Chang. 6, 827-835 (2016).

17. Knutti, R. \& Rogelj, J. The legacy of our $\mathrm{CO}_{2}$ emissions: a clash of scientific facts, politics and ethics. Clim. Change 133, 361-373 (2015).

18. Matthews, H. D., Solomon, S. \& Pierrehumbert, R. Cumulative carbon as a policy framework for achieving climate stabilization. Phil. Trans. R. Soc. Lond. A 2012 4365-4379 (1974)

19. Matthews, H. D. \& Solomon, S. Atmosphere. Irreversible does not mean unavoidable. Science 340, 438-439 (2013).

20. Solomon, S. Pierrehumbert, R., Matthews, D. \& Daniel, J. in Climate Science for Serving Society—Research, Modeling and Prediction Priorities (eds Hurrell, J. \& Asrar, G.) 506 (Springer, 2013).

21. Solomon, S. et al. Persistence of climate changes due to a range of greenhouse gases. Proc. Nat/ Acad. Sci. USA 107, 18354-18359 (2010).

22. Minx, J. C. et al. Negative emissions-Part 1: research landscape and synthesis. Environ. Res. Lett. 13, 063001 (2018).

23. Fuss, S. et al. Negative emissions-Part 2: costs, potentials and side effects. Environ. Res. Lett. 13, 063002 (2018)

24. Nemet, G. F. et al. Negative emissions-Part 3: innovation and upscaling. Environ. Res. Lett. 13, 063003 (2018).

25. Williamson, $\mathrm{P}$. Emissions reduction: scrutinize $\mathrm{CO}_{2}$ removal methods. Nature 530, 153-155 (2016).

26. Bellamy, R. Incentivize negative emissions responsibly. Nat. Energy 3, 532-534 (2018).

27. The Royal Society Greenhouse Gas Removal (The Royal Society, 2018).

28. Intergovernmental Panel on Climate Change (IPCC) Climate Change 2014: Synthesis Report. Contribution of Working Groups I, II and III to the Fifth Assessment Report of the Intergovernmental Panel on Climate Change (IPCC, 2014).

29. Hallegatte, S. et al. Mapping the climate change challenge. Nat. Clim. Chang. 6, 663-668 (2016)

30. Millar, R. J. et al. Emission budgets and pathways consistent with limiting warming to $1.5^{\circ} \mathrm{C}$. Nat. Geosci. 10, 741-747 (2017).
31. Goodwin, P. et al. Pathways to $1.5^{\circ} \mathrm{C}$ and $2{ }^{\circ} \mathrm{C}$ warming based on observational and geological constraints. Nat. Geosci. 11, 102-107 (2018).

32. Tokarska, K. B. \& Gillett, N. P. Cumulative carbon emissions budgets consistent with $1.5^{\circ} \mathrm{C}$ global warming. Nat. Clim. Chang. 8, 296-299 (2018).

33. Tokarska, K. B., Gillett, N. P., Arora, V. K., Lee, W. G. \& Zickfeld, K. The influence of non- $\mathrm{CO}_{2}$ forcings on cumulative carbon emissions budgets. Environ. Res. Lett. 13, 034039 (2018)

34. Richardson, M., Cowtan, K. \& Millar, R. J. Global temperature definition affects achievement of long-term climate goals. Environ. Res. Lett. 13, 054004 (2018)

35. Schurer, A. P. et al. Interpretations of the Paris climate target. Nat. Geosci. 11, 220-221 (2018).

36. Rogelj, J. et al. Scenarios towards limiting global mean temperature increase below $1.5^{\circ} \mathrm{C}$. Nat. Clim. Chang. 8, 325-332 (2018).

37. Rogeli, J. et al. Differences between carbon budget estimates unravelled. Nat. Clim. Chang. 6, 245-252 (2016).

38. Rogelj, J., Meinshausen, M., Schaeffer, M., Knutti, R. \& Riahi, K. Impact of short-lived non- $\mathrm{CO}_{2}$ mitigation on carbon budgets for stabilizing global warming. Environ. Res. Lett. 10, 075001 (2015).

39. Friedlingstein, P. et al. Persistent growth of $\mathrm{CO}_{2}$ emissions and implications for reaching climate targets. Nat. Geosci. 7, 709-715 (2014).

40. Comyn-Platt, E. et al. Carbon budgets for 1.5 and $2^{\circ} \mathrm{C}$ targets lowered by natural wetland and permafrost feedbacks. Nat. Geosci. 11, 568-573 (2018).

41. Gasser, T. et al. Path-dependent reductions in $\mathrm{CO}_{2}$ emission budgets caused by permafrost carbon release. Nat. Geosci. 11, 830-835 (2018). This paper provides an overview of recent estimates of the impact of permafrost thawing on remaining carbon budgets.

42. Lowe, J. A. \& Bernie, D. The impact of Earth system feedbacks on carbon budgets and climate response. Phil. Trans. R. Soc. A 376, https://doi. org/10.1098/rsta.2017.0263 (2018).

43. Mengis, N., Partanen, A.-I., Jalbert, J. \& Matthews, H. D. $1.5^{\circ} \mathrm{C}$ carbon budget dependent on carbon cycle uncertainty and future non- $\mathrm{CO}_{2}$ forcing. Sci. Rep. 8, 5831 (2018).

44. Rogelj, J. et al. Mitigation choices impact carbon budget size compatible with low temperature goals. Environ. Res. Lett. 10, 075003 (2015).

45. Geden, O. Politically informed advice for climate action. Nat. Geosci. 11 380-383 (2018).

46. Peters, G. P. Beyond carbon budgets. Nat. Geosci. 11, 378-380 (2018).

47. Kriegler, E. et al. Pathways limiting warming to $1.5^{\circ} \mathrm{C}$ : a tale of turning around in no time? Phil. Trans. R. Soc. A 376, https://doi.org/10.1098/rsta.2016.0457 (2018).

48. Rogeli, J. et al. in Global Warming of $1.5^{\circ} \mathrm{C}$ : An IPCC Special Report on the Impacts of Global Warming of $1.5^{\circ} \mathrm{C}$ Above Pre-Industrial Levels and Related Global Greenhouse Gas Emission Pathways, in the Context of Strengthening the Global Response to the Threat of Climate Change, Sustainable Development, and Efforts to Eradicate Poverty (eds Flato, G., Fuglestvedt, J., Mrabet, R. \& Schaeffer, R.) 93-174 (IPCC/WMO, 2018). This special report by the IPCC applied a forerunner of the framework described in this Perspective.

49. Millar, R. J. \& Friedlingstein, P. The utility of the historical record for assessing the transient climate response to cumulative emissions. Phil. Trans. R. Soc. A 376, https://doi.org/10.1098/rsta.2016.0449 (2018).

50. Tachiiri, K., Hajima, T. \& Kawamiya, M. Increase of uncertainty in transient climate response to cumulative carbon emissions after stabilization of atmospheric $\mathrm{CO}_{2}$ concentration. Environ. Res. Lett. 10, 125018 (2015)

51. Steinacher, M. \& Joos, F. Transient Earth system responses to cumulative carbon dioxide emissions: linearities, uncertainties, and probabilities in an observation-constrained model ensemble. Biogeosciences 13, 1071-1103 (2016).

52. Ehlert, D., Zickfeld, K., Eby, M. \& Gillett, N. The sensitivity of the proportionality between temperature change and cumulative $\mathrm{CO}_{2}$ emissions to ocean mixing. J. Clim. 30, 2921-2935 (2017).

53. MacDougall, A. H., Swart, N. C. \& Knutti, R. The uncertainty in the transient climate response to cumulative $\mathrm{CO}_{2}$ emissions arising from the uncertainty in physical climate parameters. J. Clim. 30, 813-827 (2017).

54. Collins, M. et al. in Climate Change 2013: The Physical Science Basis. Contribution of Working Group I to the Fifth Assessment Report of the Intergovernmental Panel on Climate Change (eds Stocker, T. F. et al.) 1029-1136 (Cambridge Univ. Press, 2013).

This report by the IPCC provided the first assessment of TCRE

55. Leduc, M., Matthews, H. D. \& de Elia, R. Quantifying the limits of a linear temperature response to cumulative $\mathrm{CO}_{2}$ emissions. J. Clim. 28, 9955-9968 (2015)

56. Tokarska, K. B., Gillett, N. P., Weaver, A. J., Arora, V. K. \& Eby, M. The climate response to five trillion tonnes of carbon. Nat. Clim. Chang. 6, 851 (2016).

57. Haustein, K. et al. A real-time global warming index. Sci. Rep. 7, 15417 (2017).

58. Huber, M. \& Knutti, R. Natural variability, radiative forcing and climate response in the recent hiatus reconciled. Nat. Geosci. 7, 651-656 (2014).

59. Pfleiderer, P., Schleussner, C. F., Mengel, M. \& Rogeli, J. Global mean temperature indicators linked to warming levels avoiding climate risks. Environ. Res. Lett. 13, 064015 (2018).

This paper quantified the impact on remaining carbon budgets of switching between global warming definitions.

60. Morice, C. P., Kennedy, J. J., Rayner, N. A. \& Jones, P. D. Quantifying uncertainties in global and regional temperature change using an ensemble of observational estimates: the HadCRUT4 data set. J. Geophys. Res. Atmospheres 117, https://doi.org/10.1029/2011JD017187 (2012). 
61. UNFCCC Report on the Structured Expert Dialogue on the 2013-2015 Review. FCCC/SB/2015/INF.1 http://unfccc.int/resource/docs/2015/sb/eng/inf01. pdf (UNFCCC, 2015).

62. The United Nations Environment Programme (UNEP) The Emissions Gap Report 2014. (UNEP, 2014)

63. Schurer, A. P., Mann, M. E., Hawkins, E., Tett, S. F. B. \& Hegerl, G. C. Importance of the pre-industrial baseline for likelihood of exceeding Paris goals. Nat. Clim. Chang. 7, 563-567 (2017)

64. Hawkins, E. et al. Estimating changes in global temperature since the preindustrial period. Bull. Am. Meteorol. Soc. 98, 1841-1856 (2017).

65. Meinshausen, M. et al. The RCP greenhouse gas concentrations and their extensions from 1765 to 2300. Clim. Change 109, 213-241 (2011).

66. Stocker, T. F. et al. in Climate Change 2013: The Physical Science Basis Contribution of Working Group I to the Fifth Assessment Report of the Intergovernmental Panel on Climate Change (eds Stocker, T. F. et al.) 33-115 (Cambridge Univ. Press, 2013)

67. Samset, B. H. et al. Climate impacts from a removal of anthropogenic aerosol emissions. Geophys. Res. Lett. 45, 1020-1029 (2018).

68. Smith, P. et al. in Climate Change 2014: Mitigation of Climate Change. Contribution of Working Group III to the Fifth Assessment Report of the Intergovernmental Panel on Climate Change (eds Edenhofer, O. et al.) 811-922 (Cambridge Univ. Press, 2014).

69. Gernaat, D. E. H. J. et al. Understanding the contribution of non-carbon dioxide gases in deep mitigation scenarios. Glob. Environ. Change 33 , 142-153 (2015)

70. Meinshausen, M. et al. Multi-gas emission pathways to meet climate targets. Clim. Change 75, 151-194 (2006).

71. Clarke, L. et al. in Climate Change 2014: Mitigation of Climate Change. Contribution of Working Group III to the Fifth Assessment Report of the Intergovernmental Panel on Climate Change (eds Edenhofer, O. et al.) 413-510 (Cambridge Univ. Press, 2014).

72. Riahi, K. et al. The shared socioeconomic pathways and their energy, land use and greenhouse gas emissions implications: an overview. Glob. Environ. Change 42, 153-168 (2017).

73. Huppmann, D., Rogelj, J., Kriegler, E., Krey, V. \& Riahi, K. A new scenario resource for integrated $1.5^{\circ} \mathrm{C}$ research. Nat. Clim. Chang. 8, 1027-1030 (2018).

74. Huppmann, D et al. IAMC $1.5^{\circ} \mathrm{C}$ Scenario Explorer and Data hosted by IIASA https://data.ene.iiasa.ac.at/iamc-1.5c-explorer/ (Integrated Assessment Modeling Consortium and International Institute for Applied Systems Analysis, 2018)

75. Smith, C. J. et al. FAIR v1.3: a simple emissions-based impulse response and carbon cycle model. Geosci. Model Dev. 11, 2273-2297 (2018).

76. Meinshausen, M., Raper, S. C. B. \& Wigley, T. M. L. Emulating coupled atmosphere-ocean and carbon cycle models with a simpler model, MAGICC6-Part 1: model description and calibration. Atmos. Chem. Phys. 11 1417-1456 (2011).

77. Myhre, G. et al. in Climate Change 2013: The Physical Science Basis. Contribution of Working Group I to the Fifth Assessment Report of the Intergovernmental Panel on Climate Change (eds Stocker, T. F. et al.) 659-740 (Cambridge Univ. Press, 2013)

78. Kriegler, E. et al. Fossil-fueled development (SSP5): an energy and resource intensive scenario for the 21 st century. Glob. Environ. Change 42, 297-315 (2017)

79. Ehlert D \& Zickfeld, K. What determines the warming commitment after cessation of $\mathrm{CO}_{2}$ emissions? Environ. Res. Lett. 12, 015002 (2017).

80. Gillett, N. P., Arora, V. K., Zickfeld, K., Marshall, S. J. \& Merryfield, W. J. Ongoing climate change following a complete cessation of carbon dioxide emissions. Nat. Geosci. 4, 83-87 (2011).

81. Ricke, K. L. \& Caldeira, K. Maximum warming occurs about one decade after a carbon dioxide emission. Environ. Res. Lett. 9, 124002 (2014).

82. Zickfeld, K. \& Herrington, T. The time lag between a carbon dioxide emission and maximum warming increases with the size of the emission. Environ. Res. Lett. 10, 031001 (2015).

83. Frölicher, T. L. \& Paynter, D. J. Extending the relationship between global warming and cumulative carbon emissions to multi-millennial timescales. Environ. Res. Lett. 10, 075002 (2015).

84. Frölicher, T. L., Winton, M. \& Sarmiento, J. L. Continued global warming after $\mathrm{CO}_{2}$ emissions stoppage. Nat. Clim. Chang. 4, 40-44 (2014).

85. MacDougall, A. H., Zickfeld, K., Knutti, R. \& Matthews, H. D. Sensitivity of carbon budgets to permafrost carbon feedbacks and non- $\mathrm{CO}_{2}$ forcings. Environ. Res. Lett. 10, 125003 (2015).

86. Zaehle, S. et al. Evaluation of 11 terrestrial carbon-nitrogen cycle models against observations from two temperate free-air $\mathrm{CO}_{2}$ enrichment studies. New Phytol. 202, 803-822 (2014).

87. Wenzel, S., Cox, P. M., Eyring, V. \& Friedlingstein, P. Projected land photosynthesis constrained by changes in the seasonal cycle of atmospheric $\mathrm{CO}_{2}$. Nature 538, 499-501 (2016).

88. Arneth, A. et al. Terrestrial biogeochemical feedbacks in the climate system. Nat. Geosci. 3, 525-532 (2010).
This review presents an overview of terrestrial Earth system feedback mechanisms that could further affect TCRE and estimates of remaining carbon budgets.

89. Carrer, D.,Pique, G., Ferlicoq, M., Ceamanos, X. \& Ceschia, E. What is the potential of cropland albedo management in the fight against global warming? A case study based on the use of cover crops. Environ. Res. Lett. 13, 044030 (2018).

90. Allen, M. R. et al. A solution to the misrepresentations of $\mathrm{CO}_{2}$-equivalent emissions of short-lived climate pollutants under ambitious mitigation. $n p j$ Clim. Atmos. Sci. 1, 16 (2018).

91. Burke, E. J. et al. Quantifying uncertainties of permafrost carbon-climate feedbacks. Biogeosciences 14, 3051-3066 (2017).

92. Schneider von Deimling, T. et al. Observation-based modelling of permafrost carbon fluxes with accounting for deep carbon deposits and thermokarst activity. Biogeosciences 12, 3469-3488 (2015)

93. Schneider von Deimling, T. et al. Estimating the near-surface permafrostcarbon feedback on global warming. Biogeosciences 9, 649-665 (2012).

94. Schuur, E. A. G. et al. Climate change and the permafrost carbon feedback. Nature 520, 171-179 (2015)

95. Schaefer, K., Lantuit, H., Romanovsky, V. E., Schuur, E. A. G. \& Ronald Witt, R. The impact of the permafrost carbon feedback on global climate. Environ. Res. Lett. 9, 085003 (2014)

96. Koven, C. D. et al. A simplified, data-constrained approach to estimate the permafrost carbon-climate feedback. Phil. Trans. R. Soc. A 373, https://doi. org/10.1098/rsta.2014.0423 (2015).

97. MacDougall, A. H. \& Knutti, R. Projecting the release of carbon from permafrost soils using a perturbed parameter ensemble modelling approach. Biogeosciences 13, 2123-2136 (2016).

98. Schwinger, J. \& Tjiputra, J. Ocean carbon cycle feedbacks under negative emissions. Geophys. Res. Lett. 45, 5062-5070 (2018).

99. Rogelj, J. et al. Zero emission targets as long-term global goals for climate protection. Environ. Res. Lett. 10, 105007 (2015)

100. Geden, O. An actionable climate target. Nat. Geosci. 9, 340 (2016).

101. Weyant, J. Some contributions of integrated assessment models of global climate change. Rev. Environ. Econ. Policy 11, 115-137 (2017).

102. Smith, L. A. \& Stern, N. Uncertainty in science and its role in climate policy. Phil. Trans. R. Soc. A 369, 4818-4841 (2011)

103. Eyring, V. et al. Overview of the Coupled Model Intercomparison Project Phase 6 (CMIP6) experimental design and organization. Geosci. Model Dev. 9. 1937-1958 (2016).

104. Meinshausen, M., Wigley, T. M. L. \& Raper, S. C. B. Emulating atmosphereocean and carbon cycle models with a simpler model, MAGICC6_Part 2: Applications. Atmos. Chem. Phys. 11, 1457-1471 (2011)

105. Zickfeld, K., MacDougall, A. H. \& Matthews, H. D. On the proportionality between global temperature change and cumulative $\mathrm{CO}_{2}$ emissions during periods of net negative $\mathrm{CO}_{2}$ emissions. Environ. Res. Lett. 11, 055006 (2016).

106. Allen, M. R. et al. Framing and context. In Global Warming of $1.5^{\circ} \mathrm{C}$. An IPCC Special Report on the Impacts of Global Warming of $1.5^{\circ} \mathrm{C}$ Above Pre-Industrial Levels and Related Global Greenhouse Gas Emission Pathways, in the Context of Strengthening the Global Response to the Threat of Climate Change (eds Masson-Delmotte, V. et al.) 47-92 (IPCC/WMO, 2018).

Acknowledgements We acknowledge support from the European Union's Horizon 2020 Research and Innovation Programme under grant agreement number 641816 (CRESCENDO) and grant agreement number 820829 (CONSTRAIN), and from the UK Natural Environment Research Council (NERC) under project NE/N006038/1 (SMURPHS). We thank J. Cook and colleagues contributing to the IPCC Special Report on Global Warming of $1.5^{\circ} \mathrm{C}$ (ref. ${ }^{48}$ ) for comments.

Reviewer information Nature thanks Edward Parson, Nathan Gillett and Pierre Friedlingstein for their contribution to the peer review of this work.

Author contributions J.R. coordinated the paper. All authors contributed substantially to the development of the framework, its description and presentation, and the writing of the paper. C.J.S. produced Supplementary Fig. 1. J.R. carried out the comparison of remaining carbon budgets, produced Figs. 1 and 2, and led the writing of the paper.

Competing interests The authors declare no competing interests.

Additional information

Supplementary information is available for this paper at https://doi.org/ 10.1038/s41586-019-1368-z.

Reprints and permissions information is available at http://www.nature.com/ reprints.

Correspondence and requests for materials should be addressed to J.R. Publisher's note Springer Nature remains neutral with regard to jurisdictional claims in published maps and institutional affiliations.

(C) Springer Nature Limited 2019 